\title{
The role of additional and alternative education in the self-development of children and adolescents
}

\author{
Alexandr V. Kosov \\ Department of Social and \\ Organizational Psychology \\ K.E. Tsiolkovskiy Kaluga state \\ University \\ Kaluga, Russia \\ sanslav@kaluga.net
}

\author{
Galina F. Golubeva \\ Department of General and \\ Professional Psychology \\ I.G. Petrovskiy Bryansk state \\ University \\ Bryansk, Russia \\ golubeva.galia2012@yandex.ru
}

\author{
Elena M. Feshchenko \\ Department of General and \\ Professional Psychology \\ I.G. Petrovskiy Bryansk state \\ University \\ Bryansk, Russia \\ emfeshchenko@mail.ru
}

\author{
Margarita E. Kirichkova \\ Department of Social and \\ Organizational Psychology \\ K.E. Tsiolkovskiy Kaluga state \\ University, Professional \\ communications center \\ Kaluga, Moscow, Russia \\ margaritak05@mail.ru
}

\author{
Mariam R. Arpentieva \\ Department of Developmental \\ Psychology and Education, \\ K.E. Tsiolkovskiy Kaluga state \\ University \\ Kaluga, Russia \\ $\underline{\text { mariam rav@mail.ru }}$
}

\begin{abstract}
The article is devoted to the problem of selfdevelopment of children and adolescents in modern education. The authors defined additional education as an educational environment with a high pedagogical potential for solving the problems of self-development of the younger generation. The authors distinguish the basic subjective functions of the additional education of children in the development of subjectivity of the individual.
\end{abstract}

Keywords - self-development, modernization of education, selfdevelopment of the individual, freedom, responsibility, subjectivity, individualization, additional education, alternative education

\section{INTRODUCTION}

The idea of self-development is one of the most important in the modern theory of psychology and pedagogy and of modern counseling and educational practices. Today, the category of self-development is the subject of numerous psychological and pedagogical studies. Many researches of the Russian and Soviet scientists are devoted to research of selfdevelopment in education is devoted $[1 ; 2 ; 3]$. The process of self-development in modern educational policy assumes a priority. It is present as the main target in almost every educational program. Today important attention should be paid to the education in children ability to make the right choice, the formation of positive life goals and plans. This is an indicator of self-development of the individual. The upbringing of a free personality, ready to be responsibility for one's own actions, thoughts, are important tasks of modern education in Russia and in the world $[4 ; 5 ; 6]$. This target benchmark involves the realization of the subject's position of the child and the construction of a cooperative relationship between the teacher or psychologist and children or teenagers.

\section{DISCUSSION}

Russian researchers traditionally regarded "additional education", foreign researches regarded different types of adult education. It is associated with professional conversion or advanced training in a specific field [2;3]. For example, Ch. Knapper and A. Cropley define lifelong learning, which includes additional education, as a process that would "last the whole life of each individual; lead to systematic acquisition, renewal, and upgrading of knowledge, skills and attitudes, as this became necessary in response to the constantly changing conditions of modern life, with the ultimate goal of promoting self-fulfillment of each individual" [3, p. 183]. School and university students develop and meet their need for additional education as the critical way to engage in lifelong learning. It is starts in school / student days and continues throughout the life cycle. Russian and world scientists rely upon the determination theory to allow for not only extrinsic factors of development of the need for additional education (employer requirements, current trends) but also intrinsic ones (commitment to increasing one's competitiveness in the labor market, need for personal fulfillment, social and personal realizations). Self-development is an important task for almost any person, at any age and condition. However, it becomes especially important in childhood and adolescence. Childhood and adolescence are sensitive periods to self-development and to the formation of «readiness to follow the call of the potential». During this period, a person is intensively forming a reflection (self-awareness and awareness of the world) [7, p. 67]. An indispensable condition and mechanism for selfdevelopment of a person is the man' striving for reflection, for understanding as revealing or giving meaning to what is happening inside and outside the person. Life begins to be interpreted as "solving problems for meaning". The realization in psychology and pedagogy of the tasks of activating the 
processes of self-development presupposes the search and application of new approaches to the upbringing and education of children and teenagers. A modern educational organization must be ready and capable of designing a global environment that can create the prerequisites and conditions for children's self-development and social implementations. This environment should give each child or teenager the choice of ways and means to achieve personally significant goals. Specially organized psychological and pedagogical conditions and technologies are very important factor in the selfdevelopment of today's students (A.G. Asmolov, B.S. Bratus', F.Ye. Vasiluk, L.S. Vygotsky, A.N. Leontiev, D.A. Leontiev, J. Bugental, R. May, V. Frankl and others) [2]. It is also important to take into account the interrelation and harmony of self-realization and social realization, for example, the needs as such are formed under the influence of extrinsic and intrinsic factors predetermining all human life. Every action should be correlated with the opportunities offered by nature and society and one's personal willingness to grasp them. By accepting everyday life requirements imposed by the society, one can turn the public demand for (self-)education into their own intrinsic motivator [8, p. 30-37]. Reflecting on a purposeful, systemic movement towards solving the tasks of activating the self-development of the younger generation, modern scholars make a special emphasis on the realization of additional education. Additional education for children (and adults) is a kind of education that is aimed at fully satisfying the educational needs of a person in intellectual, spiritual, moral, physical and (or) professional development and is not accompanied by a formal increase in the level of education (attestation). Additional education is an essentially motivated education that allows the learner to acquire a stable need for cognition and creativity. It allows you to maximize yourself, to be self-determined professionally and personally. Many researchers consider the additional education of children as a purposeful process of education and training through the implementation of additional educational programs $[8 ; 9 ; 10]$. Additional education for students is often included in the system of continuing education. Training takes place in specialized institutions of additional education for children, as well as in profile centers created directly in schools. Alternative education appeared up in response to the establishment of standardized and compulsory education over the last centuries. Specialists, Educators and other professionals, philosophers and other scientists including J.-J. Rousseau, J.H. Pestalozzi; A.B. Alcott, R.W. Emerson, and H. D. Thoreau; J. Dewey and F. Parker, F. Fröbel, M. Montessori and R. Steiner believed that education should cultivate the «developing child» and "self-developing child" on many aspects: not only physically, but also psychologically, morally and spiritually [3]. The Russian experience of extracurricular (additional) education is unique in world pedagogical practice. However, it is based on the advanced tradition of the pedagogical ideas of many other countries. In addition, this experience has become an example of additional education in other countries, especially in Eastern Europe, China, Cuba, Vietnam, etc. Separate elements of the system of out-of-school education are developing in the countries of Asia and Europe. For example, the experience of extracurricular education was applied to the adaptation of former young Soviet citizens in Israel. In Japan, there is a free practice of compulsory participation of each student in additional classes. These lessons are not included in the school curriculum (optional). After World War II an alternative R. Emilia and L. Malaguzzi approach to childhood education was developed $[13 ; 14 ; 15]$. Usually these are classes in physical culture, artistic creation, and national arts, etc. In most European countries there is a system of "service club", "hobby clubs", fancier associations and clubs catering to specific interests (interest associations / interest club). Usually this system exists under the aegis of municipalities, public and religious organizations. In pedagogical practice, these activities are usually called «nonformal education», an alternative education ("open systems", "distance learning", "non-conventional studies", "autonomous learning" "homeschool", etc.). Alternative education encompasses many very different pedagogical approaches formally and meaningfully differing from mainstream pedagogy. Such alternative learning environments can be provided by public (state), charter, and independent schools as well as home-based learning environments. Families seeking alternatives for educational, philosophical, ethno-cultural or religious reasons, or if there is no nearby educational alternative may opt for home-based education. Some homeschool families form a cooperative, where parents with expertise in a subject may teach children from a number of families while their children are taught by other parents. Autodidacticism ore self-directed inquiry is recognized at all levels of education, from the «unschooling» of children to the autodidacticism of adults. It may occur separately from (or with) traditional forms of education [16; 17]. Autonomous learning is a homeschool of education which sees learners as individuals who can and should be autonomous. These schools helps students develop their self-consciousness, understanding and comprehension, practicality and freedom of discussion. Different indigenous cultural and historical educational alternatives suggest work in small class sizes, close relationships between students and teachers and a sense of community and psychological safety. "Natural learning" is a type of learning-on-demand. In this type, children pursue knowledge based on their interests. Parents take an active part in facilitating activities and experiences conducive to learning. However, parents do not rely heavily on textbooks or spend much time "teaching", looking instead for «learning moments» throughout their daily activities. Parents see their role as that of affirming through positive feedback and modeling the necessary knowing and skills. The child's role as being responsible for asking and learning. There is also the term "unschooling" as coined by J. Holt. This term describes an approach in which parents do not authoritatively direct the child's education, but interact with the child following the child's own interests, leaving them free to explore and learn as their interests lead [17]. "Unschooling" does not indicate that the child is not being educated, but that the child is not being "schooled", or educated in a classic school-type manner. J. 
Holt noted that children learn through the experiences of life. He encouraged parents "to live their lives with their child". Also known as interest-led or child-led learning, unschooling attempts to follow opportunities as they arise in real life, through which a child will learn without coercion.

Another proponent of unschooling is J.T. Gatto, he argues that public education is the primary tool of «state controlled consciousness» and serves as a prime illustration of the total institution - a social system, which impels obedience to the state and quells free thinking or dissent [18]. The real function of classical pedagogy, he argues, is to render the common population manageable. This pedagogy (as "Weapons of Mass Instruction") inflicts is rational and deliberate and very often cripple imagination, discourage critical thinking, and create a false view of learning as a byproduct of rote-memorization drills. To that end, young and other age people must be conditioned to rely upon teachers as experts, to remain divided from specific alliances, and to accept disconnections from their own lived experiences. They must at all costs be discouraged from developing self-reliance and independence. Escaping this trap requires strategy J. Gatto calls "open source learning". This learning imposes no artificial divisions between learning and life. Through this alternative approach, children and other students can avoid being indoctrinatedonly then that can they achieve self-knowledge, good judgment and world-understanding and courage.

The term "unschooling" was coined and used by educator J. Holt, "the father of unschooling" [17; 20]. Unschooling encourages exploration of activities initiated by the children themselves. Unschooling believing that the more personal learning is, the more meaningful, well-understood and useful it is to the student. Unschooling advocates learner-chosen activities as a primary means for learning. Unschoolers may question the school environment as one that is optimal for daily learning. According to Brain Rules by J. Medina, "If you wanted to create an education environment that was directly opposed to what the brain was good at doing; you probably would create something like a classroom..." [21]. Unschooling students learn through their natural life experiences and personal interests and curiosity (play and household responsibilities, internships and work experience, books and elective classes, travel and mentors, family and social interaction). Critics of unschooling see it as an extreme educational philosophy, with concerns that unschooled children will lack the social skills, structure, and motivation of their schooled peers, while proponents of unschooling say exactly the opposite is true: self-directed education in a natural environment better equips a child to handle the "real world" [22]. Many other forms of alternative education also place a great deal of importance on student control of learning, albeit not necessarily of the individual learner. This includes free democratic schools. Unschoolers sometimes state that learning any specific subject is less important than learning how to learn. They assert, in the words of J. Holt: "Since we can't know what knowledge will be most needed in the future, it is senseless to try to teach it in advance. Instead, we should try to turn out people who love learning so much and learn so well that they will be able to learn whatever must be learned" [17, p. 210].

In whole alternative pedagogical approaches may include different structures and concepts, as in the open classroom, different teacher-student relationships, as in the Quaker and free schools, and/or differing curricula and teaching methods, as in the Waldorf and M. Montessori schools.[1] Synonyms for "alternative" in this context include «non-traditional", "non-conventional" and "non-standardized». Alternative educators very often use words such as "authentic', "developmental", "contextual", "holistic" and "progressive", "innovative", "creative", "decentralized education", "egalitarian, democratic, socially responsible program" [2]. Some elements of the system of extracurricular education were perceived in the countries of Asia and Europe. For example, the experience of extracurricular education was postponed for the adaptation of former young Soviet citizens in Israel. There is a free practice of compulsory participation of each student in additional classes in Japan. These lessons are not included in the school curriculum (optional). Usually these are classes in physical culture, artistic creation, and national arts, etc. There is a system of clubs for interests in most European countries. Usually this system exists under the aegis of municipalities, public and religious organizations, and on parental means also. In pedagogical practice, these activities are usually called «non-formal education», an alternative education [12]. In Non-formal learning includes various structured learning situations. The learner's objectives may be to increase skills and knowledge, as well as to experience the psychological rewards associated with love for a subject or passion for learning [23]

The legal and formal framework for such education varies by locality, and determines any obligation to orient with mainstream standard school tests and criteria's (grades). It also orient in culture, religious and other indigenous traits of the region / community. R. Miller has identified five elements common to educational alternatives (the transition from the modern institution of mass schooling to a postmodern network of diverse learning options available to all people): respect for the person, balance of the interpersonal relations, decentralization of authority, noninterference among the political, economic, and cultural spheres of society, a holistic and sacral worldview [11]. Modern educational transformation bridging the divide between conventional «liberal» and «conservative» educational policies, include grassroots movement for educational transformation, grounded in these principles, is spontaneously emerging. This is the SelfOrganizing Revolution in mass and public schooling. This approach is the basis of transcendence of the specific methodologies used by different educational approaches.

Cl. Zaki wrote, that "Formal education corresponds to a systematic, organized education model, structured and administered according to a given set of laws and norms, presenting a rather rigid curriculum as regards objectives, content and methodology. It is characterized by a contiguous education process named... "presential education", which necessarily involves the teacher, the students and the 
institution" [24, p. 300]. "The methodology is basically expositive, scarcely relating to the desired behavioral objectives - as a matter of fact, it is but seldom that such targets are operationally established. The objectives aimed at the personal growth of students are negligence and, the basic principles of learning fail to be considered in the planning and the performance of education systems..." [24, p. 300-301]. A very important point is the simulation of education: "in the case of formal education, for the most part teachers pretend to teach; students pretend to learn; and, institutions pretend to be really catering to the interests of students and of the society. Thus, generally, formal education cannot disguise its aloofness from the real needs of the students and of the community." [24, p. 301].

Another definition (the CEDEFOP places) of classical, formal education is: "Formal learning: learning typically provided by an education or training institution, structured (in terms of learning objectives, learning time or learning support) and leading to certification. Formal learning is intentional from the learner's perspective" [25, p. 32]. Compared with formal education, informal learning is "learning resulting from daily life activities related to work, family or leisure. It is not structured (in terms of learning objectives, learning time or learning support) and typically does not lead to certification. Informal learning may be intentional but in most cases it is not-intentional (or "incidental" / "random)" [25, p. 32-33]. In whole, "It is difficult to make a clear distinction between formal and informal learning as there is often a crossover between the two" $[26$, p. 1, 19], «the terms informal and nonformal appeared interchangeable, each being primarily defined in opposition to the dominant formal education system, and the largely individualist conceptualizations of learning developed in relation to such educational contexts». Moreover, he states that "It is important not to see informal and formal attributes as somehow separate, waiting to be integrated". [27, p. 314].

M. Eraut defines formal learning as taking place within a learning framework; within a classroom or learning institution, with a designated teacher or trainer; the award of a qualification or credit; the external specification of outcomes. Any learning that occurs outside of these parameters is nonformal $[28$, p. 12]. The EU places non-formal learning in between formal and informal learning (see above). This has learning both in a formal setting with a learning framework and as an organized event but within a qualification. «Nonformal learning: learning that is not provided by an education or training institution and typically does not lead to certification. However, it is structured (in terms of learning objectives, learning time or learning support). Non-formal learning is intentional from the learner's perspective.» $[25, \mathrm{p}$. 32-33]. S. Billet's definition states all human activity is learning, and that everything people do involves a process of learning. «all learning takes place within social organizations or communities that have formalized structures», and most learning in life takes place outside of formal education [29, p. $12 ; 30]$. That, this is the dominant view in the science and it is mistaken [31]. However, their distinction is still important in the context of differences in ideas about the education of children and adults, the influence of the previous experience of education and life on the current process. The fields of adult education and human resource development have evolved from simply positing that adults learn differently from children continues to be quite evident in this revised edition. The Adult Learner reflects its own subject matter by thoughtfully integrating new topics to the discussion. In addition, outside and before andragogic and gerontogogic research, education for adults and the elderly was really "alternative". In the education of children, the concept of "alternative education" emphasizes the freedom of choice and "complementarity" of selected extra-curricular and curricular (classroom) activities.

In Russia, additional training is not primarily an alternative, but it is in addition to teaching traditional. Until the midtwenties of the XX century, it naturally complemented the development of students. However, because of destructive reforms (the abandonment of technology and teaching methods used in the Russian gymnasiums before the revolution and soon after), it tried to compensate for the gaps that have arisen in the process of standardizing education. This he did not quite succeed, since the additional training itself was standardized. A new stage of additional training began with the end of the twentieth century: the next reform completed the collapse of education in Russia. Additional education, including in the forms described above (selfeducation, home education, etc.) has become an important aspect of compensating for the core gaps.

Additional education is a search, variation education that tests other, «not common» ways out of various vague situations arising in culture. This education, which gives the personality a fan of the possibilities of choosing one's destiny, stimulating the processes of personal self-development" $[1$, p. 6]. Development of the education system in the Russian Federation and other countries involves using the potential of additional education for children as an important moment of creating an environment for the self-development of the learner's personality. The additional education of children is the most important component of the educational space that has developed in Russian society. It is socially in demand by children and teenagers, parents and educators, and society as a whole, combines the upbringing, education and development of the child's or teenager's personality [8]. However, compared with the Soviet period, especially the period until the middle of the twentieth century, it is much less qualitatively organized and with less success is used. In education there are more declarations and formalism (fictions) and less real appeal to improve the quality of education: society

and the state educate children and adolescents to serve their own interests, regardless of the interests of the students themselves, the interests of the individual.

Pedagogical activity in the additional education of children is aimed at supporting children and teenagers, searching in the pupil for individual abilities and talents. The activity of the teacher is aimed at activating the student's inner potential. It is 
also aimed at creating optimal conditions for development as self-realization not only social implementation [8, p. 215-216]. Additional education for children has acquired a new status today. The demand for additional education for children as the most important component of the educational space of the modern Russian society is reflected in the country's educational policy. The main goal of modern education is the preparation of a multifaceted personality of a citizen, oriented in the traditions of national and world culture. The goal of modern education is the preparation a citizen, oriented in the modern system of values and the needs of modern life, capable of active social adaptation in society and an independent life choice, and the continuation of vocational education, self-education and self-improvement. Additional and alternative education has a special role in the development of abilities and interests, personal, social and professional selfdetermination of children, adolescents and youth.

Modern alternative or additional education provide children and teenagers with the opportunity to freely choose various forms and activities, participate in amateur activities, develop their social and creative activity, aspiration to participate in various socially significant projects, in socially useful activities together with teachers and parents.

Modern alternative or additional education also provide them with the opportunity to receive additional education. It is very important for the Government to give children the opportunity to freely choose various forms and activities, participate in amateur activities. This requires the development of their social and creative activity, the support the desire of children and teenagers to participate in various socially significant projects, in socially useful activities in conjunction with teachers and parents [10]. For additional education of children, an indicative orientation toward creating conditions for the development of individuality, attention e to support the independence, self-determination of each child, personal growth and self-development [5, p. 49]. "In the field of additional education, we give the opportunity to become a person, not just the opportunity to choice of subjects. Additional education has always been truly variable: the child does not come to him from under the stick, here is not training, but the preparation of the opportunity to be. He is doing another; today the most important thing in life is to look for the meaning of life and the opportunity to be. He tries himself in different roles, and this is the great thing and the essence of additional education. In fact, additional education is a zone of proximal development for the formation of Russia" $[1$, p. 8]. It is evident that scientists and practices see the value of additional education for children and teenagers in the development of the child's and teenager's propensities and abilities, self-education and self-determination, self-realization and social implementation, and also in mastering of experience and value relations and inclusion of the child and teenager in dialogical and creative search. Thus, "having arisen, the phenomenon began to live an independent life and turned out to be much stronger and broader than it was conceived at creation" [6, p. 29].
"The student need for additional education is determined by both extrinsic and intrinsic factors. Such factors are formed by the current trends" on the one hand, and «"by the desire to get certified in innovative fields of science, engineering and social process management, on the other hand" [2, p. 221]. The development of the need for additional education is affected greatly by the relevant experience during the years of studies. "Those with the previous experience are able to make a more reasonable choice of further educational and career trajectories and to assess the value of new courses they are offered" within the educational program. "As students develop specific needs for supplementary knowledge, new forms of teacher-student interaction in the learning process evolve. The role of students in the educational process organization is changing, making them the customers of new knowledge ensuring their personal fulfillment and successful employment" [2, p. 221].

To psychological and pedagogical possibilities of additional and alternative education of children and adolescent, contributing to theirs self-development and social implementation, modern scientists relates:

- the variability and non-standard content and forms of the organization of classes and activities, consisting in the organization of a variable educational process with nonstandard, non-regulated topics, time frames and forms of teaching and educational work, the selection of individual educational programs, topics studied with different speed of assimilation;

- a variety of subjective educational interaction to meet the child's need for confidential communication, a comfortable environment for cooperation, co-creation and partnership of the teacher and student, ensure the implementation of an individual approach in socially significant activity, creating a trusted space for constructive interaction;

- the presence of original social samples that provide a targeted choice of various types of socially significant activity, socio-cultural technologies that integrate pedagogical capabilities with the development of the child and his individual abilities to absorb social values, knowledge, and skills [9].

It is possible to intensively activate the processes of selfrealization and self-development of people. This can be done by relying on the distinctive, potentially competitive features of the additional education of children and adolescents. The main aspects of this process are:

- $\quad$ creation of conditions for free choice by each child and teenager of the educational area, creation of conditions for free choice by each child and teenager of the program profile and teacher;

- personally active character of the educational process, contributing to the development of motivation for cognition and creativity, self-realization and social implementation;

- personally oriented approach to the child or teenager, creating a situation of success for everyone; a variety of activities that satisfy the child's and teenager's interests and needs; recognition of the right to trial and error in choice, 
revision of opportunities for self-determination and social implementation $[4 ; 5 ; 8]$.

The researcher identifies the following basic subjective functions of the additional education of children in the development of subjectivity and self-development of children: 1) the development of essential forces and abilities that enable the learner to choose the optimal life path strategies, including due to the variability and integrativity of complementary education manifested in the expansion educational space of the student;

2) education of the initiative and responsibility of students, including due to the value of additional education, such as children's self-government, which presupposes responsible performance of various social roles;

3) provision of conditions for the life self-determination of the child, including through the practical orientation of additional education for the development of competences in the chosen field of activity;

4) mastering the students' means of achieving a subjective position, including through the adaptability of additional education, which implies the possibility of mastering the totality of forms and methods of effective moral behavior, successful socialization;

5) creation of conditions for the development of independence, individuality of the trainee. These conditions are realized and thanks to this possibility of additional education, as an individualized social and pedagogical support of the student $[3 ; 34 ; 35]$.

\section{RESULTS}

The theoretical analysis of the works of Russian and other educators allows us to conclude that additional and alternative educations for children and adolescents has specific characteristics that are necessary for the self-development process, namely:

- $\quad$ Additional education acts as a vital activity, as an ongoing process of the goal-setting, creativity and life choices (acts) of a person. The life-activity nature of additional education is carried out through the construction and realization of the relations of joint creativity (co- creativity) of all subjects of the educational process;

- $\quad$ additional and alternative educations of children and adolescents involves subjectivity, motivation for selfdevelopment through the creation of subject-subject relationships between participants in the educational process;

- $\quad$ additional and alternative educations of children and adolescents suggests the realization of activity, initiative, independence of the individual, the formation of an active life position through the personal orientation of the educational process, its focus on the maximum self-realization of the individual and the individuality of all subjects of education process ;

- $\quad$ additional and alternative educations of children and adolescents $n$ provides the opportunity for freedom of choice, awareness and realization of responsibility for the choice made before oneself and the world. Thus, additional and alternative educations makes it possible to develop subjectivity. In the context of additional and alternative educations the student acts as an actor, a subject of activity, including educational activity;

- $\quad$ additional and alternative educations of children and adolescents creates the conditions for the formation of moral qualities of the individual, awareness of actions and deeds through the creation of an educational environment saturated with traditions and methods of work that maximally take into account the characteristics of society / region;

- $\quad$ additional and alternative educations of children and adolescents provides mastery of reflection and self-control in the course of carrying out creative and routine activities, in educational, professional, family and friendly,

- $\quad$ additional and alternative educations of children and adolescents contributes to the formation and development of strong-willed personality. It achieves this through the use of specific forms and methods of education and upbringing, correction and development peculiar to supplementary education;

- $\quad$ Additional and alternative educations of children and adolescents creates the conditions for the development of congruence of the individual. It also creates opportunities for preventing the dis-adaptation of children and adolescents in school and in life. Prevention and correction of violations teachers carry out, structuring the strength and time of children and adolescents. Teaching children and adolescents creative activities that meet their needs and abilities stimulates the development of self-understanding. The use of healthsaving educational technologies by teachers is included in the implementation of support and support for the development of each child and teenager. Thus, additional and alternative educations are designed to meet the vital and diverse life and educational needs of children and teenagers. It helps to reduce the negative consequences of unemployment of children in their spare time, teaches them to structure their lives in such a way as to realize their own goals and abilities, and not destroy themselves and their lives. Children and teenager are «supervised». Awareness of the presence of such «supervision» creates a state of psychological security, significance for the world. It helps to cope with difficulties and take steps into the unknown: into the unknown inner and outer world.

\section{CONCLUSION}

The additional and alternative educations of children and adolescents today plays an important role in resolving the issues of education vital for the child and adolescents, organizing leisure, choosing a circle of contacts, life values and landmarks, professional self-determination, self-development and personality. Special contribution is made by additional education in the upbringing and development of children and adolescents, who face the most important problems of professional self-determination and personal self-forecasting. Very important in this area is initiative and complexity. This initiative should be directed to create a sustainable multi-level system for extracurricular child and teenager education based on a public-private partnership and implementation of state-of- 
the-art supplementary education programs to identify and further every child's and teenager's talents.

\section{REFERENCES}

[1] A.G. Asmolov, "Additional education as a zone of the nearest development in Russia: from traditional pedagogy to pedagogy of development", in Transcript of the interregional meeting-seminar on the problem «Increasing the level of management of the development of additional education for children. Petrozavodsk, 1996, March 13-15, pp. 6-8. (In Russian)

[2] A. Merenkov, A.Sushchenko, "How university students develop and meet their need for additional education", in Voprosy obrazovaniya / Educational Studies. Moscow, 2016, vol. 3, pp. 204-223.

[3] B. Grummell, "The 'Second Chance' Myth: Equality of Opportunity in Irish adult education policies", in British Journal of Educational Studies, 2007, vol. 55, 2, pp. 182-201.

[4] M. Gorshkov, G. Klyucharev, "Lifelong Learning in the Context of Modernization", Moscow: Institute of Sociology, Russian Academy of Sciences; Center for Strategic Studies, Federal State Scientific Institution, 2011, pp. 220-245. (In Russian)

[5] M.R Arpentieva, "Transgression and transcendence in personal development", in Materials of the 4th International Conference "Process Management and Scientific Developments" (Birmingham, United Kingdom, February, 2018). Birmingham, United Kingdom, Scientific publishing house Infinity, 2018, pp. 50-64.

[6] E.V. Seredintseva, "On the Priority of Additional Education". Vneshnikolnik, 1997, vol. 4, pp. 29-31. (In Russian)

[7] A.S. Sukhorukov, "Life-creating personality in the dynamics of its semantic system". Dis. .. PhD in psychol. sciences. Moscow: Moscow State University, 1997, 141 p. (In Russian)

[8] A. Merenkov, "Human Activity Determination System". Yekaterinburg: Ural Academy of Mining and Geology; Bank of Cultural Information, 2003, pp. 30-37. (In Russian)

[9] M.R. Arpentieva, "Psychodiagnostics of the style of educational activity and psychodynamics of personal development", in International Scientifical Practical Conference «Building globalised World: social, economic, political Perspectives of Education» Proceedings. October 31, 2017, Kostanay. Kazakhstan, Kostanay: Kostanay State Pedagogical Institute, Shadrinsky State Pedagogical University, 2017, pp. 55-62. (In Russian)

[10] M.R Arpentieva, “ The ideological problems of education and social differentiation. Innovations in science, education and production of Kazakhstan (on 17-18 November 2016): Materials of internationalscientific and practical conference". Almaty: Eurasian University of Technology, 2016, vol. 1, pp. 78-79. (In Russian)

[11] R. Miller, "Self-Organizing Revolution", New York: Alternative Education Resource Organization , Holistic Education Press, 2014, $112 \mathrm{p}$.

[12] J.Sybille-Christin, D.J.Drewes, "Aus der Waldorf-Schule geplaudert. Warum die Steiner-Pädagogik keine Alternative ist". Aschaffenburg: Alibri, 2001, 340p.

[13] C.V. Korn, "Alternative American Schools: Ideals in Action". Ithaca, New York: SUNY Press (State University of New York Press), 1991, 190p.

[14] E.J. Trickett, "Living an Idea: Empowerment and the Evolution of an Alternative High School". Maryland : University of Maryland, Brookline Books, 1999237p.

[15] Ch.J. Churchill, and E.L. Gerald, "The Enigmatic Academy: Class, Bureaucracy, and Religion in American Education", Philadelphia, PA: Temple University Press, 2012, 234p.

[16] Ch. D. Hayes , "Self-University: The price of tuition is the desire to learn: your degree is a better life". New York: Autodidactic, 1989, 220p.
[17] J. Holt, Instead of education: ways to help people do things better. Boulder, CO: Sentient Publications, 2004, 250p.

[18] J.T. Gatto "Weapons of Mass Instruction". New York: Odysseus Group, New Society Publishers, 2010, 210p.

[19] S.Chang- Martin, O. Gould, \& R. Meuse, "The impact of schooling on academic achievement: evidence from homeschooled and traditionally schooled students". Canadian Journal of Behavioural Science, 2011, vol. 43(3), pp.195-202. doi:10.1037/a0022697

[20] B. Ray, "Research facts on homeschooling". New York: NHERI Publications (National Home Education Research Institute), 2016, 224p.

[21] J. Medina, "Brain Rules: 12 Principles for Surviving and Thriving at Work, Home, and School". Seattle, WA: Pear Press, 2014, 304p.

[22] K. Rolstad, K. Kesson, "Unschooling, Then and Now". Journal of Unschooling and Alternative Learning, 2013vol. 7 (14), pp.33-38.

[23] Ph.Hodkinson, H.Colley, M. Janice, “ The Interrelationships Between Informal and Formal Learning", in Journal of Workplace Learning, 2003, vol. 15, pp. 313-318.

[24] Cl. Zaki, "Formal, non-formal and informal education: concepts/applicability.", in Cooperative Networks in Physics Education - Conference Proceedings 173", Interamerican Conference on Physics Education", Oaxtepec, Mexico, 1987. New York: American Institute of Physics, 1988, pp. 300-315.

[25] CEDEFOP (European Centre for the Development of Vocational Training) "Terminology of European education and training policy: a selection of 130 terms". Luxembourg: Publications Office, 2014, pp. 3233. URL: $\quad$ http://www.cedefop.europa.eu/en/events-andprojects/projects/validation-non-formal-and-informal-learning/europeaninventory/european-inventory-glossary (accessed 10.02.2018)

[26] V. McGivney, "Informal learning in the community: a trigger for change and development". Leicester: NIACE, 1999. pp. 1-19.

[27] Ph. Hodkinson, H. Colley, J. Malcolm,. "The Interrelationships Between Informal and Formal Learning", in Journal of Workplace Learning, 2003 , vol. 15 , pp. 313-318.

[28] M.Eraut, "Non-formal learning, implicit learning and tacit knowledge", in F. Coffield (Ed) The Necessity of Informal Learning. Bristol: Policy Press, 2000. - 180p.

[29] S. Billett, "Participation and continuity at work: A critique of current workplace learning discourses". Context, Power and Perspective: Confronting the Challenges to Improving Attainment in Learning at Work. Conference Sunley Management Centre, University College Northampton, $8^{\text {th }}-10^{\text {th }}$ November. Northampton, 2001, pp. 12-14.

[30] H.Colley, Ph. Hodkinson \& J. Malcolm, "Non-formal learning: mapping the conceptual terrain. A Consultation Report". Leeds: University of Leeds Lifelong Learning Institute, 2002, 320p. URI: http://eprints.hud.ac.uk/id/eprint/13176 (accessed 10.02.2018)

[31] D.Joostenten Brinke, D.Sluijsmans, W. Jochems, "Support in Assessment of Prior Learning: Personal or Online?", in: D.Joostenten Brinke, M. Laanpere (eds) Technology Enhanced Assessment. TEA 2016. Communications in Computer and Information Science, vol 653. Springer, Springer International Publishing AG, Cham, 2017, pp. 4762. doi: https://doi.org/10.1007/978-3-319-57744-9 5

[32] M.S. Knowles, E.F. Holton, R.A. Swanson, "The adult learner: the definitive classic in adult education and human resource development", New York, Routledge, 2015, 402p.

[33] M.C. Miguel, J.H. Ornelas, J.P. Maroco, "Recognition of prior learning: the participants' perspective", in Stud. Contin. Educ. 2016, vol. 2, pp. $1-$ 16 doi: 10.1080/0158037X.2015.1061491

[34] M.R. Arpentieva, N.S. Korchagina, "Personal readiness of students of the faculties of social work and professional activities". North Carolina: Lilu, Si-press, 2017. 240p.

[35] J. M. Gidley, G.P. Hampson, "The evolution of futures in school education", in Futures, 2005, vol. 37 (4), 255. doi:10.1016/j.futures.2004.07.005. 